\title{
Psychiatric aspects of heart transplantation: preoperative evaluation and postoperative sequelae
}

\author{
FRANCOIS M MAI, F NEIL MCKENZIE, WILLIAM J KOSTUK
}

\begin{abstract}
The contribution of a liaison psychiatrist to a cardiac transplant programme is described. Ninety one patients were referred to the transplant unit for assessment over four years, and of these, 86 were assessed by the psychiatrist. A high prevalence of preoperative anxiety and depression was found.

Thirty four transplants were performed on 33 patients during the study and 22 patients survived. Six patients developed transient delirious episodes during the first 10 postoperative days, three showed symptoms of considerable anxiety, and three developed social and behavioural problems during the convalescent period. Subjects with higher scores on the somatic scale of the general health questionnaire showed increased postoperative mortality.

In conclusion, the liaison psychiatrist is useful in evaluating and managing heart transplant patients before and after operation.
\end{abstract}

\section{Introduction}

Progressive improvement in the techniques of cardiac surgery together with the emergence of cyclosporin as a powerful immunosuppressive agent have led to a resurgence of interest in cardiac transplantation. Nearly half of patients who have grafts survive at

University of Western Ontario, Ontario, Canada

FRANCOIS M MAI, MD, FRCPED, professor, departments of psychiatry and medicine

F NEIL MCKENZIE, MB, FRCS, professor, department of medicine

WILLIAM J KOSTUK, MD, FRCPC, professor, department of medicine (also chief of cardiology, University Hospital)

Correspondence to: Dr Mai, Department of Psychiatry, University Hospital, London, Ontario, Canada N6A 5A5. five years, which is comparable with the results after cadaveric renal transplantation. ${ }^{1}$ Rehabilitation in survivors has also been good, so there will probably be a substantial increase in the number of institutions offering this procedure.

Despite the psychiatric and social implications of the procedure few studies have been published of this aspect of the operation. Lunde reported on the psychiatric complications in the early period of the Stanford programme ${ }^{2}$ and Christopherson described the programme from the social worker's perspective. ${ }^{34}$ More recently, Jamieson (personal communication) reported that at Stanford psychiatrists were concerned with the programme on a consultative basis only. In a general article on the psychological adjustment associated with cardiac transplantation Allender et al described possible reactions that may occur during various stages of the process. ${ }^{5}$ Freeman et al described preliminary observations on the evaluation of heart transplant candidates. ${ }^{6}$ They were "struck by the incidence of anxiety, depression, and organic mental disorders" in their series of nine subjects. A detailed psychiatric case study was published recently on Barney Clark, who was the first recipient of an artificial heart. ${ }^{7}$

At this hospital 34 heart transplants were performed on 33 patients from April $1981 .^{8}$ Twenty two patients survived. A psychiatrist (FM) was a fully active member of the transplant team from its inception. ${ }^{9}$ All patients referred for assessment had psychiatric evaluation, and this information was considered along with the biological data in forming an overall evaluation. We report here on the psychiatric contribution to the programme and the results of psychiatric assessments before and after the operation.

\section{Patients and methods}

Each patient had a psychiatric evaluation within a few days of his hospital admission. A modified form of the present state examination was used; it is a widely used investigative technique in psychiatric research. ${ }^{10}$ Using a semistructured approach, it covers symptoms referable to the various psychodiagnostic categories. Because our population was not primarily 
psychiatric yet was suffering from severe (and often terminal) medical illness, the present state examination was abbreviated by eliminating those sections concerned primarily with psychotic illness. A brief series of ratings was added to evaluate additional items thought to have particular relevance to transplantation. These items included histories of alcohol abuse, compliance with medical treatment, attitude towards surgery, expectations regarding postoperative care, and attitude towards death and dying. Finally, the patient was questioned about his personal and social history to ascertain his personality, social circumstances, and network of support. At the end of the interview the patient was given the general health questionnaire $(60 \text { items })^{11}$ and the symptom check list $90^{12}$ to complete.

Those patients who survived the operation were seen a year later when the present state examination, general health questionnaire, and symptom check list 90 were repeated. In addition, the psychiatrist was available for clinical consultation. Several patients were seen and treated for various psychiatric problems arising from the operation and its sequelae.

\section{Results}

\section{PREOPERATIVE DATA}

Of the 91 patients referred to the unit for consideration of surgery, 86 ( 75 men) were assessed by the psychiatrist. Of the five patients not seen for assessment, two died shortly after admission, the assessment for transplant was cancelled for two, and one received the transplant on an urgent basis without a psychiatric assessment. Twenty of the 86 subjects did not receive a present state examination, nor did they complete the symptom check lis ${ }^{+90}$ and general health questionnaire. These included the first 12 subjects who were seen for a general psychiatric examination without undergoing a present state examination, and eight subjects who were judged to be too ill medically to undergo the procedural formalities. Of the remaining 66 patients, 26 were diagnosed as being in a state of anxiety, seven had simple depression, one had "other" depression, and 32 were not diagnosed.

Most subjects (48 (72\%)) showed appropriate apprehension concerning the postoperative period, although a few were excessively apprehensive (three $(5 \%)$ ) or defensive $(13(20 \%))$. Most were also aware of the risks and limitations of surgery $(52(79 \%))$. Concerning attitude towards their own death, 19 out of $61(31 \%)$ were anxious, 18 out of $62(29 \%)$ showed denial, and 24 out of $62(39 \%)$ showed acceptance; 47 out of $58(81 \%)$ showed accepting attitudes towards a foreign organ and 11 out of $58(19 \%)$ denial.

The mean preoperative score of the general health questionnaire in the subjects who did not have the operation was $6 \cdot 28$, compared with $6 \cdot 16$ in those who had the transplant (NS). The results of the symptom check list 90 also showed no significant differences between those who had and those who did not have the operation.

\section{POSTOPERATIVE DATA}

Of the 33 patients ( 30 men) who had an operation, 22 survived. Six (18\%) experienced acute delirium during the first 10 postoperative days. In three this was transient and did not require pharmacotherapy; in the other three it was more severe and required intensive neuroleptic treatment, with close monitoring of dose and response. All made a good recovery.

Four patients, one of whom died from a viral infection 42 days after the operation, developed moderately severe anxiety, and three developed social or behavioural problems, or both. There were no diagnoses of depression from the present state examination in the five patients who were seen at follow up at 12 months. One subject, however, was diagnosed with clinical depression six months after surgery and responded well to antidepressant treatment. The psychosocial adjustment of the remaining subjects who developed postoperative psychiatric problems seemed to have improved at the time of their last follow up.

Preoperative total and somatic scores of general health questionnaire in survivors and non-survivors of transplant

\begin{tabular}{|c|c|c|c|c|c|}
\hline & $\begin{array}{l}\text { No of } \\
\text { cases }\end{array}$ & $\begin{array}{l}\text { Mean }(\mathrm{SD}) \\
\text { score }\end{array}$ & $t$ Value & $\mathrm{df}$ & $\begin{array}{c}\text { One tail } \\
\text { probability }\end{array}$ \\
\hline \multicolumn{6}{|c|}{ Total scores } \\
\hline $\begin{array}{l}\text { Survivors } \\
\text { Non-survivors }\end{array}$ & $\begin{array}{r}10 \\
8\end{array}$ & $\begin{array}{r}8 \cdot 60(9 \cdot 96) \\
13 \cdot 87(9 \cdot 12)\end{array}$ & $-1 \cdot 16$ & 16 & 0.13 \\
\hline \multicolumn{6}{|c|}{ Somatic scores } \\
\hline $\begin{array}{l}\text { Survivors } \\
\text { Non-survivors }\end{array}$ & $\begin{array}{r}10 \\
8\end{array}$ & $\begin{array}{l}2 \cdot 60(3 \cdot 24) \\
5 \cdot 25(3 \cdot 28)\end{array}$ & -1.71 & 16 & 0.05 \\
\hline
\end{tabular}

Also of great interest were the verbal responses to the graft. These results will be published separately. In describing their feelings concerning the graft and donor a high proportion (59 (90\%)) expressed overt uninterest and denial.

The table compares the preoperative scores of the general health questionnaire in those who survived the operation with the scores of those who died. Non-survivors tended to show significantly higher scores on the somatic dimension of the general health questionnaire.

\section{Discussion}

The high prevalence of psychiatric problems in both patients evaluated preoperatively as part of their assessment for possible transplant and those seen postoperatively indicates that the liaison psychiatrist is a valuable member of the heart transplant team.

Other than the high predominance of men $(75$ out of $86(87 \%)$ ) the patients assessed preoperatively probably represent a random sample of the community aged 50 or under. Most patients experienced symptoms of anxiety or depression, or both, at the time of their preoperative assessment ( 34 out of $66(52 \%)$ ). This has also been described among renal transplant recipients, ${ }^{13}$ when it was noted that depression tended to occur among the recipients preoperatively but in the donors postoperatively. In most cases this was the result of the acute distress associated with their severe medical problems. Some had experienced psychiatric problems and treatment previously, and this may have sensitised them to react to the severe stress of their deteriorating health. Treatment in these cases was directed towards the symptoms of their underlying cardiac problems, supportive counselling, and, in some patients, the administration of mild sedation or hypnotics, or both. In none of these cases did the presence of these symptoms influence the decision of whether to proceed with surgery.

The psychiatric problems that followed surgery were interesting; postoperative delirium is a common problem after cardiac surgery, and excellent reviews have been published on this topic. ${ }^{14}$ is Of the 33 patients who received grafts, six experienced acute delirious psychoses postoperatively, but in only three were these severe enough to require neuroleptic treatment. This proportion is comparable with that described in cardiac bypass surgery. ${ }^{16}{ }^{17}$ Our figures were based on a careful review of the daily postoperative record. This method probably underestimates the true incidence. Kornveld noted that the incidence of postoperative delirium of $27 \%$ when based on chart review rose to $70 \%$ when based on psychiatric assessment. ${ }^{16}$ We could not confirm the conclusion of Layne and Yudofsky that those with minimal anxiety preoperatively had a higher likelihood of postoperative delirium. ${ }^{18}$ Our figures are also comparable with those reported by Hotson and Pedley. ${ }^{19}$ In a retrospective study of the neuropsychiatric sequelae in 83 patients who had heart transplants they found that seven (12\%) developed metabolic encephalopathy and seven others developed acute psychosis. Our use of psychoactive drugs has been conservativethat is, they have not been used unless restlessness, agitation, and psychotic phenomena have been severe and progressive and have not responded to simpler, non-pharmacological treatment such as support, encouragement, and destimulation.

Three patients developed anxiety symptoms postoperatively and had all been noticeably anxious preoperatively. They were treated with a combination of supportive psychotherapy, relaxation therapy, and benzodiazepines, largely with a good response. In the remaining subjects preoperative anxiety or depressive symptoms did not predispose to postoperative psychopathology. Indeed, the psychiatric symptoms largely disappeared once these subjects recovered medically.

The three patients with postoperative behavioural and psychosocial problems were in some ways the most complex from the point of view of management. In all three the operation seemed to accentuate recognised pre-existing problems. These difficulties were compounded by conflicts in the family; tensions between the patient, his family, and various staff members; and the attendant publicity of the operation. Considerable time was spent by medical, psychiatric, and social work staff in resolving these problems, with satisfactory results in all three cases. 
The finding that subjects who scored higher on the somatic scale of the general health questionnaire were significantly more likely to die during the postoperative period is of interest. A similar tendency was noted in the total score of the general health questionnaire, but the difference here was not significant. The somatic scale rates various physical symptoms according to whether that symptom has recently increased in intensity. Thus this result indicates that those subjects who exhibit recent symptomatic deterioration represent an increased surgical risk. The symptomatic deterioration in turn probably reflects that the progression of their cardiac disease is accelerating. Nevertheless, the number in our series was small, so this part of the study should be replicated using a larger sample.

\section{PSYCHIATRIC REQUIREMENTS FOR SURGERY}

Members of the team have spent considerable time discussing the psychiatric and psychosocial conditions that need to be met to proceed with transplant surgery (if this is indicated by medical criteria). Anxiety and depressive symptoms secondary to their serious medical disorder were not considered to be contraindications to surgery. More difficulty was experienced with patients with a personality disorder. If this was characterised by recent alcoholism or drug abuse these were considered to be absolute contraindications to surgery. It was thought that these patients, because of their behaviour, would not be able to comply with the complex physical, psychological, and pharmacological requirements of the postoperative period. Less severe disturbances of personality were considered relative contraindications only-for example, if the patient's organic condition indicated the need for an operation such disturbances were not seen as contraindications. Despite these considerations six of the patients who underwent the operation experienced psychiatric or psychosocial difficulties of at least moderate intensity.

Good family and social support systems were regarded as important requirements for surgery. The extended convalescence and increased dependence emphasise the importance of a family who evidently care for each other. The operation and postoperative period may be times of severe physical and psychological stress, which may tax a family in which relationships are not firm and mature. Recently, however, two middle aged men with minimal social support underwent transplantation. One made a satisfactory adjustment, and the convalescence of the other was prolonged but ultimately satisfactory.

Clearly good motivation is a requirement for operating. In general we have not had to question the motivation of the patient. By the time of assessment for the operation all our patients have been aware of the severity of their medical condition and prognosis and that transplant surgery was probably their only hope of survival. Thus by virtue of admitting themselves to hospital for assessment for the operation they showed their strong motivation for help. We have looked for but not found patients who seemed ambivalent about the operation but who were under strong family or social pressure to proceed. It is important, therefore, to ensure that the patient is informed about the operation and its risks, that he is not ambivalent in his motives, and that he is not under external-that is, spousal, family, or social-pressure to have the operation. In seven of the 66 patients seen preoperatively such personality and psychosocial factors were influential in deciding against surgery. Finally, it is important to ensure, as part of the examination on mental state, that the patient does not show serious cognitive dysfunction. If this is present a complete neurological evaluation, including electroencephalography and computed tomography should be carried out to rule out irreversible organic brain disease, which would contraindicate transplant surgery.

Our findings are, of necessity, preliminary and tentative. This is a new surgical aspect, the number of patients was small, and there are few previous reports with which these results can be compared. Nevertheless, with the success of the antirejection drugs and improvements in the technical proficiency of the operation there is no question that more cardiac transplant units will be established over the next decade. We hope that liaison psychiatrists will be in the front line of this development, using their skills to ensure that increased life expectancy is associated with a commensurate improvement in the quality of life of the survivors.

We thank Mr Gary Wood and Ms Susan Escaf for analysing and processing the statistical data and Mrs Anne Welch for preparing the manuscript.

\section{References}

1 Pennock JL, Reitz BA, Beiber CP, Stinson EB. Cardiac transplantation in perspective for the future. F Thorac Cardiovasc Surg 1982;83:168-77.

2 Lunde D. Psychiatric complications of heart transplants. Am f Psychiatry 1969;126:368-73.

3 Christopherson LK, Griepp RB, Stinson EB. Rehabilitation after cardiac transplantation. fAMA 1976;236:2082-4.

4 Christopherson LK. Cardiac transplantation: need for patient counselling. Nursing Mirror 1979;149:34-6.

5 Allender J, Shisslak C, Kaszniak A, Copeland J. Stages of psychological adjustment associated with heart transplantation. Heart Transplantation 1983;ii:228-31.

6 Freeman A, Watts D, Karp R. Evaluation of cardiac transplant candidates: preliminary observations. Psychosomatics 1984;25:197-207.

7 Berenson C, Grosser B. Total artificial heart transplantation. Arch Gen Psychiatry 1984;41:910-6. 8 McKenzie N, Kostuk W, Stiller C, Keown P, Mai F, Silver M. Heart and heart-lung transplantation at the University Hospital. Journal of Heart Transplantation 1984;iv:20.

9 Mai FM, McKenzie FN, Kostuk WJ. Liaison psychiatry in a heart transplant unit. Psychosom Med 1984;46:80-1.

10 Wing JK, Cooper J, Sartorius N. The measurement and classification of psychiatric symptoms. Cambridge: Cambridge University Press, 1974:189-228.

11 Goldberg D. The detection of psychiatric illness by questionnaire. Oxford: Oxford University Press, 1972. (Maudsley Monograph No 22 .)

12 Derogatis L. Administration, scoring and procedures manual for the SCL 90 . Baltimore: Johns Hopkins University, 1977:2-62.

13 Kemph J. Psychotherapy with patients receiving kidney transplant. Am f Psychiatry 1967;124: 623-9.

14 Dubin W, Field H, Gastfriend D. Post-cardiotomy delirium: a critical review. $\mathcal{J}$ Thorac Cardiovas Surg 1979;77:586-93.

15 Lipowski Z. Delirium: acute brain failure in man. Springfield, Illinois: C Thomas, 1980:500-7.

16 Kornveld D, Zimberg S, Malm J. Psychiatric complications of open heart surgery. $N$ Engl $\mathcal{F}$ Med 1965;273:287-92.

17 Rabiner C, Willner A, Fishman J. Psychiatric complications following coronary bypass surgery. $\mathcal{J}$ Nerv Ment Dis 1975;160:342-8.

18 Layne O, Yudofsky S. Postoperative psychosis in cardiotomy patients. N Engl $\mathcal{f}$ Med 1971;284:518-20.

19 Hotson J, Pedley T. The neurological complications of cardiac transplantation. Brain 1976;99. 673-94.

(Accepted 14 October 1985)

How dangerous is exposure to materials containing isocyanate in a paint spraying workshop? Should the concentration of isocyanate in the air be monitored, and should the employees be screened for lung disease by radiography or spirometry?

It is difficult to quantify how "dangerous" exposure to isocyanates is, but it is known to cause upper respiratory tract irritation and occupational asthma. Occupational asthma affects about $5 \%$ of workers exposed to toluene diisocyanate, the most commonly used isocyanate, ${ }^{\prime}$ and has been reported in paint sprayers, ${ }^{2}$ who may be affected by isocyanates from respirable aerosols produced by spraying. The concentration of isocyanate in air should be monitored, preferably by personal sampling rather than by static measurements. The concentration should be kept as far below the control limit as possible by use of local exhaust ventilation, electrostatic precipitation, etc, but if such control measures are not practicable appropriate respiratory protection must be provided. ${ }^{3}$

It is necessary to screen employees, as sensitive individuals may develop occupational asthma at levels of exposure below the control limit. ${ }^{2}$ It may be desirable to screen out those who suffer from eczema, asthma, or hay fever, although the routine exclusion of asymptomatic atopics-that is, those with positive skin prick tests to non-specific allergens-is probably unnecessary. Spirometry is the mainstay of inpost screening and is recommended for employees exposed to isocyanates, as impairment of lung function may be the earliest sign of developing respiratory sensitisation and removal from exposure at this stage may prevent the development of overt asthma. As most cases arise during the first year of exposure, and a substantial proportion during the first two months, spirometry should be carried out at two weeks, six weeks, and six months after the beginning of exposure and six monthly thereafter. Routine chest radiography plays little part.-W R LEE, professor, and A R SCOTT, lecturer, in occupational health, Manchester.

Parkes WR. Occupational lung disorders. 2nd ed. London: Butterworths, 1982:432.

2 O'Brien IM, Harries MG, Burge PS, Pepys J. Di-isocyanate induced asthma. 1. Reactions to TDI, MDI, HDI and histamine. Clin Allergy 1979:9:1-6.

3 Health and Safety Executive. Isocyanates: toxic hazards and precautions. (Guidance note EHI6.) London: HMSO, 1984. 